\title{
The impact of endemic and epidemic malaria on the risk of stillbirth in two areas of Tanzania with different malaria transmission
} patterns

\author{
Ulrika Uddenfeldt Wort $^{1}$, Ian Hastings ${ }^{2}$, TK Mutabingwa ${ }^{3,4}$ and \\ Bernard J Brabin*2,5,6
}

Address: ${ }^{1}$ Division of International Health (IHCAR), Karolinska Institutet, Stockholm, Sweden, ${ }^{2}$ Child and Reproductive Health Group, Liverpool School of Tropical Medicine, Pembroke Place, Liverpool L3 5QA, UK, ${ }^{3}$ Gates Malaria Partnership, London School of Hygiene and Tropical Medicine, London, UK, ${ }^{4}$ National Institute of Medical Research, Dar es Salaam, Tanzania, ${ }^{5}$ Emma Kinderziekenhuis, Academic Medical Centre, University of Amsterdam, The Netherlands and ' Royal Liverpool Children's Hospital NHS Trust, Alder Hey, Liverpool, UK

Email: Ulrika Uddenfeldt Wort - ulrikauddenfeldt@yahoo.se; Ian Hastings - hastings@liv.ac.uk; TK Mutabingwa - tkmuta@tanga.net; Bernard J Brabin* - b.j.brabin@liv.ac.uk

* Corresponding author

Published: 17 October 2006

Malaria Journal 2006, 5:89 doi:10.1 186/1475-2875-5-89

This article is available from: http://www.malariajournal.com/content/5/l/89

(c) 2006 Wort et al; licensee BioMed Central Ltd.

This is an Open Access article distributed under the terms of the Creative Commons Attribution License (http://creativecommons.org/licenses/by/2.0), which permits unrestricted use, distribution, and reproduction in any medium, provided the original work is properly cited.

\begin{abstract}
Background: The impact of malaria on the risk of stillbirth is still under debate. The aim of the present analysis was to determine comparative changes in stillbirth prevalence between two areas of Tanzania with different malaria transmission patterns in order to estimate the malaria attributable component.
\end{abstract}

Methods: A retrospective analysis was completed of stillbirth differences between primigravidae and multigravidae in relation to malaria cases and transmission patterns for two different areas of Tanzania with a focus on the effects of the El Niño southern climatic oscillation (ENSO). One area, Kagera, experiences outbreaks of malaria, and the other area, Morogoro, is holoendemic. Delivery and malaria data were collected over a six year period from records of the two district hospitals in these locations.

Results: There was a significantly higher prevalence of low birthweight in primigravidae compared to multigravidae for both data sets. Low birthweight and stillbirth prevalence (I7.5\% and $4.8 \%)$ were significantly higher in Kilosa compared to Ndolage (II.9\% and 2.4\%). There was a significant difference in stillbirth prevalence between Ndolage and Kilosa between malaria seasons $(2.4 \%$ and $5.6 \%$ respectively, $\mathrm{p}<0.00 \mathrm{I}$ ) and during malaria seasons ( $\mathrm{I} .9 \%$ and $5.9 \%$ respectively, $\mathrm{p}<0.00 \mathrm{I}$ ). During ENSO there was no difference $(4.1 \%$ and $4.9 \%$, respectively). There was a significant difference in low birthweight prevalence between Ndolage and Kilosa between malaria seasons $(14.4 \%$ and $23.0 \%$ respectively, $p<0.00 \mathrm{I})$ and in relation to malaria seasons $(13.9 \%$ and $25.2 \%$ respectively, $\mathrm{p}<0.00 \mathrm{I})$. During ENSO there was no difference $(22.2 \%$ and $19.8 \%$, respectively). Increased low birthweight risk occurred approximately five months following peak malaria prevalence, but stillbirth risk increased at the time of malaria peaks.

Conclusion: Malaria exposure during pregnancy has a delayed effect on birthweight outcomes, but a more acute effect on stillbirth risk. 


\section{Background}

Stillbirth is an important indicator of the quality of obstetric care. The highest rates of stillbirth occur in developing countries, especially sub-Saharan Africa, and averages 2040/1000 births [1]. Malaria can cause serious complications in pregnancy, such as anaemia, low birthweight, preterm delivery, and maternal mortality. The reductions in birthweight occur particularly in primigravidae in areas with an endemic malaria transmission pattern [2-7].

The impact of malaria on the risk of stillbirth and neonatal mortality is still under debate. Malaria could increase stillbirth risk through low birthweight, foetal anaemia or preterm delivery [8]. Neither McGregor et al., in the Gambia [3], nor Anagnos et al. in Zaire [9], detected any statistical association between stillbirth and placental malaria. McGregor et al. reported some seasonal differences in stillbirth rates, with the lowest rate occurring during the three months of the late dry season when placental malaria prevalence was low. This difference occurred across all parities. Conversely Okoko et al., also in the Gambia, observed a two-fold increased risk of stillbirth among mothers with malaria-infected placenta [10]. Recently, van Geertruyden et al. reached the same conclusion based on a meta-analysis of 17 cross-sectional studies mostly from Africa [1]. They also concluded that the foetal mortality rate was doubled in malaria endemic countries (40.1/1000, 95\% CI; 32.1-48.0), compared to nonendemic countries (20.0/1000, 95\% CI; 13.2-26.8). These studies were hospital based, parity was not taken into account and most were from highly malarious areas.

Stillbirth is common in areas with unstable malaria [1113] and amongst refugees [14]. Newman et al. reported a seven-fold increased risk of stillbirth in association with placental parasitaemia in areas with unstable malaria transmission [15]. All of these studies were confounded by non-malaria related causes of stillbirth, which may relate to history of recurrence [16]. Methodologies to estimate the malaria-attributable component are difficult to establish. In view of the association of malaria with low birthweight and the El Niño southern climatic oscillation (ENSO) [57], this natural phenomenon facilitates estimation of malaria attributable stillbirths related to peak periods of malaria exposure, or to epidemic malaria, which can occur at these times.

The aim of the present analysis was to determine comparative changes in stillbirth and low birthweight prevalence between two areas of Tanzania with different malaria transmission patterns in order to estimate seasonal changes and the malaria attributable component.

\section{Methodology \\ Study area Kagera (Ndolage mission hospital)}

This region is situated in the north-west corner of Tanzania, and is an area with endemic malaria and strong seasonality. Kagera is one of the poorest regions in Tanzania. Most women of reproductive age are subsistence farmers who cultivate plantains, maize, cassava, rice and millet. Ndolage hospital, in Muleba district (formerly Bukoba rural district) is situated $60 \mathrm{~km}$ south of Bukoba town, at an altitude of 1,600 metres above sea level. It is a mission hospital with approximately 1,400 deliveries a year, contributing to approximately $45 \%$ of the deliveries in the hospital catchment area. The state-run antenatal clinics do not provide antimalarial prophylaxis, but those run by the churches sometimes do (chloroquine $300 \mathrm{mg}$ base once weekly at the time of the study). The effectiveness of chloroquine prophylaxis was greatly limited by poor compliance and high levels of chloroquine resistance [18].

Retrospective data was collected for deliveries at Ndolage hospital for the years 1994-1999. Information from delivery books was transcribed to data sheets and entered into an SPSS data file. Data on stillbirth, birthweight, parity and twin birth were collected. Records included both macerated and fresh. The data on peripheral blood smear examination for malaria parasites was obtained from laboratory record books for the same period of deliveries. Malaria smears were routinely taken from all in and outpatients with malaria-like symptoms who visited the hospital. Quality control of malaria microscopy was not available, but the hospital technicians were experienced malaria microscopists. Data on all diagnosed malaria cases admitted to the paediatric ward was collected. Data on rainfall was available locally from Bukoba Meteorological Station.

Malaria-related climatic effect on the risk of low birthweight was considered to be greatest a number of months into a peak period of malaria transmission, as a longer duration of malaria exposure during pregnancy would increase the risk of birthweight reduction. It was predicted this effect would occur three months after the malaria peak and that it would last 5 months. This approximation was made following an analysis of data from an earlier study in Kagera region $[7,17]$. It was assumed that the increased risk of stillbirth would last as long as the malaria season lasted. The rainy season was defined as rainfall $>80$ $\mathrm{mm} /$ month. In some years a clear seasonal rainfall pattern was observed even if monthly values did not fall below 80 $\mathrm{mm}$. The malaria season was defined as a change in prevalence from baseline value which averaged $>150$ positive malaria slides per month (all ages) (Figure 1). This represented a weighted average estimate for positive slides. Seasonal trends were assessed. At the time of the study, 
treatment failures with chloroquine $(25 \mathrm{mg} / \mathrm{kg})$ were $50 \%$ at day 14 following treatment [18].

To compare the results from the two study areas, the study period was divided into three groups in relation to seasonal intensity of malaria transmission: between malaria seasons, during malaria seasons (stillbirths), in relation to malaria seasons (low birthweight) and El Niño Southern Oscillation (ENSO). This was one of the worst El Niño ever recorded and lasted between November 1997 and August 1998. The El Niño rains in Kagera came with strong winds, which uprooted plantain the staple food leading to increased famine, especially as El Niño was followed by a subsequent drought.

\section{Study area Morogoro (Kilosa district hospital)}

This region is situated in central Tanzania and is an area with holoendemic malaria transmission with seasonal peaks $[19,20]$. Apart from the Uluguru mountain ranges, most $(80 \%)$ of the region is flat, with a risk of standing water following the rainy period. Most women are subsistence farmers who cultivate maize, cassava, rice and shogum. Kilosa hospital has 150 beds and 1200-1400 deliveries a year representing approximately $35 \%$ of deliveries in the catchment area. Data were available from Kilosa Hospital for the years 1994-1999 and from the local meteorological station. Data on peripheral blood smear examination for malaria parasites was available from laboratory books from 1997-1999. The staff at the nine antenatal clinics visited, and the doctor in charge of Kilosa hospital stated that malaria prophylaxis, or preventive antimalarial treatment was not given routinely. Data on clinically diagnosed malaria cases from the paediatric ward was also collected to confirm malaria seasons. The rainy season was as defined in Kagera region. The malaria season in Kilosa was defined similar to that in Ndolage hospital, as a change in prevalence from a baseline value which for Kilosa was $>450$ positive malaria slides per month (Figure 2). This was the weighted average estimate for this area [7]. For Kilosa, the different malaria seasons were defined as in Kagera. ENSO in Kilosa also came with heavy rainfall, but did not cause any malaria epidemic. At the time of the study clinical chloroquine treatment failures (all ages) at day 14 following treatment were $72 \%$ [18].

Data was entered into SPSS ${ }^{\circledast}$. A logistic regression model was used, with separate analysis for low birthweight and stillbirth). Only one predictor variable was used, that of risk period (as defined above) as a fixed factor. The reference category was deliveries/stillbirths that occurred outwith the defined risk periods. Categorical data were evaluated using chi-square tests. A two-sided $p$ value of $<$ 0.05 was considered statistically significant. Low birthweight was defined as less than 2,500 grams. Twin births and stillbirths were excluded in the low birthweight calculations as their inclusion gave skewed results. Twin births were excluded in the stillbirth calculations for the same reason.

These studies received ethical approval by the Ethical Committee at the National Institute for Medical Research in Tanzania. Permission to undertake the study was granted by the Evangelical Lutheran Church of Tanzania (Ndolage hospital) and the District Medical Officer in charge of Kilosa hospital.

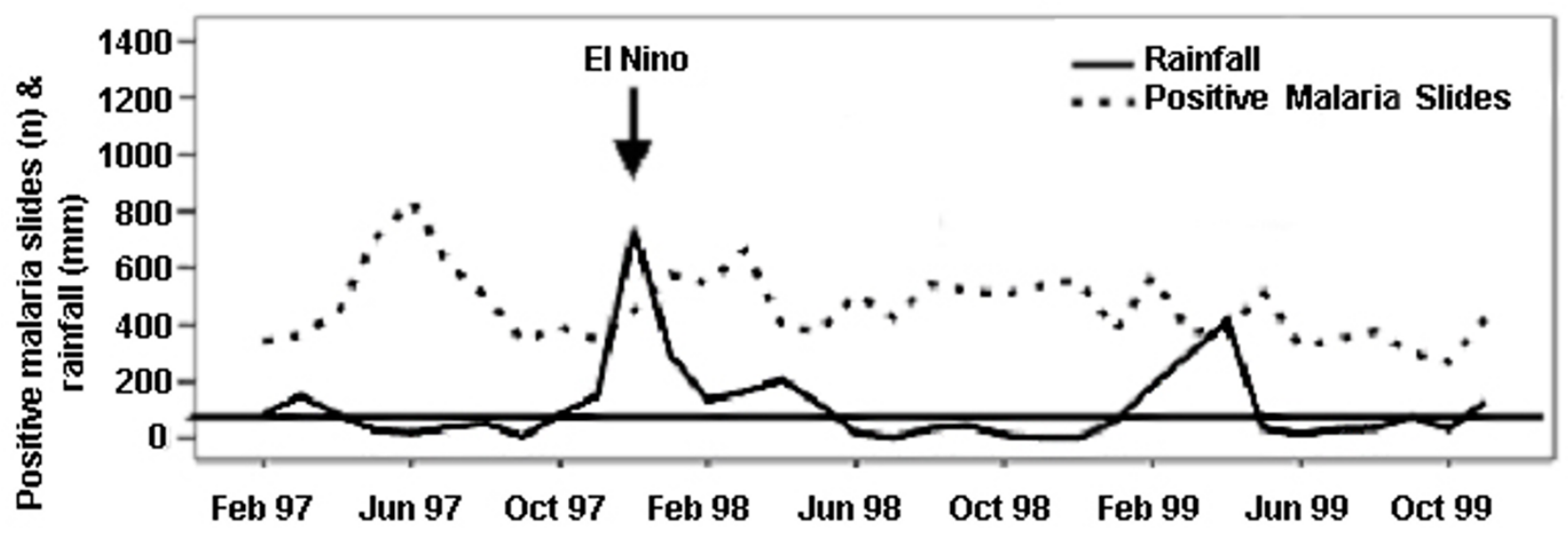

Figure I

Positive malaria slides at Ndolage hospital and rainfall in Bukoba District (1994-1999). 


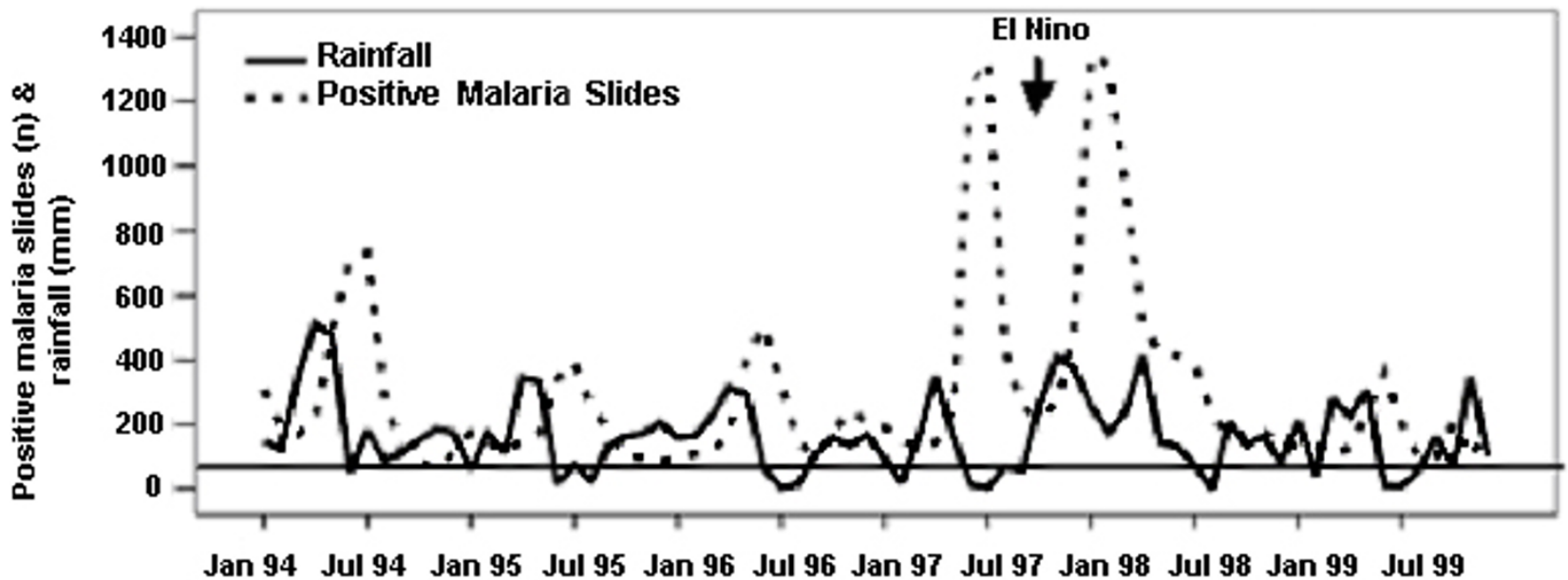

Figure 2

Positive malaria slides at Kilosa hospital and rainfall in Kilosa District (1997-1999).

\section{Results}

Descriptive data on low birthweight and stillbirth for the two study areas are summarised in Table 1. There was a significantly higher prevalence of low birthweight in primigravidae compared to multigravidae in both study areas (Ndolage, odds ratio $(\mathrm{OR})=2.0 ; 95 \% \mathrm{CI}, 1.7-2.3$; Kilosa, 2.7; 2.4-3.1). Primigravidae from Kilosa showed significantly higher low birthweight prevalence compared to Ndolage $(\mathrm{p}<0.001)$. There was also significantly higher stillbirth prevalence in Kilosa, with a trend to higher prevalence with increasing gravida.

\section{Kagera region (Ndolage hospital)}

The rains in Kagera were seasonal (Figure 1). All rainy periods were followed by malaria seasons, with one exception (July-December 1994). For two periods the short and the long rains merged into long rainy periods both lasting 9 months. The first was from September 1995-May 1996 and the average rainfall per month was low. The second lasted from October 1997-June 1998 and was the worst ENSO recorded.
Malaria seasons lasted for 2-4 months, with three exceptions. In April-August 1994 the malaria season lasted for 5 months. It was a recognized heavy malaria season with an average of 488 positive malaria slides per month. In April-September 1995 the season lasted for 6 months but was less impressive (250 slides/month). The heaviest malaria season, which was epidemic, was during the ENSO months between November 1997 and August 1998. It lasted 10 months with 631 positive malaria slides per month. June-September 1997 was another exceptional malaria period (820 positive malaria slides/ month), although short (4 months) and not preceded by high rainfall. Between these rainy seasons, there was a considerably smaller malaria risk. Diagnosed malaria in children in the paediatric ward and positive malaria slides for the whole population showed good temporal correspondence.

Between 1994 and 1999 there were 7,825 singleton live and stillbirths at Ndolage hospital, of which $0.2 \%$ had missing data. The proportion of primigravidae births

Table I: Birth outcomes from Ndolage and Kilosa hospitals, 1994-1999

\begin{tabular}{|c|c|c|c|c|c|c|c|c|}
\hline \multirow[t]{2}{*}{ Hospital } & \multirow{2}{*}{$\begin{array}{l}\text { Sample } \\
\text { size }\end{array}$} & \multirow{2}{*}{$\begin{array}{l}\text { Proportion deliveries } \\
\text { in first pregnancy } \\
(95 \% \mathrm{Cl})\end{array}$} & \multicolumn{3}{|c|}{ Prevalence low birthweight* $(95 \% \mathrm{Cl})$} & \multicolumn{3}{|c|}{ Prevalence all stillbirths $(95 \% \mathrm{Cl})$} \\
\hline & & & All & PG & MG & All & PG & MG \\
\hline Ndo & 7,825 & $36.8(35.8-37.9)$ & $11.9(11.2-12.6)$ & $16.2(\mid 4.9-17.6)$ & $9.4(8.6-10.2)$ & $2.4(2.0-2.7)$ & $1.7(12-2.1)$ & $2.6(2.1-3.0)$ \\
\hline Kilosa & 7,350 & $39.7(38.6-40.8)$ & $17.5(16.6-18.4)$ & $25.5(23.9-27.1)$ & $12.2(11.2-13.2)$ & $4.8(4.3-5.3)$ & $4.2(3.4-4.9)$ & $5.2(4.5-5.8)$ \\
\hline
\end{tabular}

* twins and stillbirth excluded, risk period for low birthweight is calculated to start 3 months after the peak malaria period and to last for 5 months. 
Table 2: Logisitic regression of risk of stillbirth in all deliveries and of low birthweight in primigravidae, 1994-1999; one predictor was fitted in each analysis i.e. risk period as defined in the main text. Overall significance of risk period in Ndolage for stillbirth and LBW was $p=0.002$ and $p=004$ respectively, and for Kilosa was $p=0.55$ and $p=0.25$ respectively

\begin{tabular}{|c|c|c|c|c|c|}
\hline \multirow[t]{2}{*}{ Malaria season } & \multicolumn{2}{|c|}{ OR for stillbirth } & \multirow[t]{2}{*}{ Risk period* } & \multicolumn{2}{|c|}{ OR for lbw in PG* } \\
\hline & Ndolage & Kilosa & & Ndolage & Kilosa \\
\hline $\begin{array}{l}\text { Between malaria } \\
\text { seasons }\end{array}$ & Reference & Reference & $\begin{array}{l}\text { Between risk } \\
\text { periods }\end{array}$ & Reference & Reference \\
\hline Dec 93-Feb 94 & $0.7(0.3-1.6)$ & $N / A$ & April 94-Aug 94 & I.I (0.8-I.7) & $N / A$ \\
\hline April 94-Aug 94 & $1.3(0.8-2.2)$ & $\mathrm{N} / \mathrm{A}$ & Sep 94-Jan 95 & $1.7(1.2-2.5)^{\S}$ & N/A \\
\hline April 95-Sep 95 & I.3 (0.8-2.I) & $N / A$ & Sep 95-Jan 96 & $1.4(0.9-2.0)$ & $N / A$ \\
\hline April 96-July 96 & $0.6(0.3-1.4)$ & $N / A$ & Aug 96-Dec 96 & $0.7(0.4-1.2)$ & $N / A$ \\
\hline Oct 96-Jan 97 & $0.4(0.1-1.1)$ & $\mathrm{N} / \mathrm{A}$ & Feb 97-June 97 & $1.0(0.6-1.5)$ & $\mathrm{N} / \mathrm{A}$ \\
\hline Jun 97-Aug 97 & $0.4(0.1-1.2)$ & $1.2(0.7-2.1)$ & Sep 97-Jan 98 & $0.6(0.3-1.0)$ & $1.0(0.7-1.4)$ \\
\hline Nov 97-Aug 98** & $1.9(1.3-2.9)^{\dagger}$ & $0.8(0.6-1.2)$ & April 98-Aug 98 & $1.7(1.1-2.6)^{\S}$ & $0.8(0.6-1.2)$ \\
\hline May 99-July 99 & $1.6(0.9-2.9)$ & $0.9(0.5-1.6)$ & Aug 99-Dec 99 & $1.2(0.8-1.7)$ & $1.3(0.9-2.0)$ \\
\hline
\end{tabular}

* twins and stillbirth excluded, risk period for low birthweight is calculated to start 3 months after the peak malaria period and to last for 5 months.

**ENSO, ${ }^{\dagger} \mathrm{p}=0.001,{ }_{\mathrm{p}}=0.01$

(36.8\%) was above that expected for a rural hospital in a developing country [21] (Table 1). The period for highest risk of low birthweight in primigravidae compared to multigravidae was calculated as commencing three months after the major malaria peak and lasting for five months [7]. Two major risk periods for increased prevalence of low birthweight in primigravidae were recognized, one was in relation to the heavy malaria season April-August 1994 (OR = 1.7; 95\% CI, 1.2-2.5, $\mathrm{p}=0.007$ ) and the other one was in relation to ENSO (OR $=1.7 ; 95 \%$ $\mathrm{CI}, 1.1-2.6, \mathrm{p}=0.013)$. ENSO was the only identified risk period for increased prevalence of stillbirth $(\mathrm{OR}=1.9$; 95\% CI, 1.3-2.9, $\mathrm{p}=0.001$ ), (Table 2).

For the years 1994-1999, the prevalence risk of stillbirth was compared between and during normal malaria seasons and during ENSO. The prevalence of low birthweight between and in connection with malaria seasons and in connection with the two heavy malaria seasons 1994 and 1997-1998 (ENSO) was also compared. Low birthweight prevalence in primigravidae did not differ greatly between periods between or in relation to normal malaria transmission ( $14.3 \%$ and $14.7 \%$ respectively), but significantly increased in primigravidae during 1994 and ENSO to $22.0 \%(\mathrm{p}=0.002)$. Stillbirth prevalence increased during ENSO for both primigravidae and multigravidae, although this was significant only for multigravidae $(\mathrm{p}=$ 0.018 ) and only for those with birthweight $2.5 \mathrm{~kg}$ and above $(p=0.02)$. Macerated stillbirth prevalence was $50 \%$, fresh stillbirth $21 \%$ and undefined stillbirths $29 \%$. Regression analysis for stillbirth risk for the individual months for combined years was significant for October (2.6; 95\% CI, 1.1-6.1).

\section{Morogoro region (Kilosa hospital)}

Rainfall showed a seasonal pattern (Figure 2) which was not as marked as in Kagera. The short and long rains often merged into a period lasting approximately 4 months, with $400-600 \mathrm{~mm}$ rainfall. As in the Kagera, October 1997-May 1998 was an exceptionally heavy rainy season $(1884 \mathrm{~mm})$.

Malaria data was available only from April 1995 (diagnosed malaria cases in the paediatric ward) and from January 1997 (positive malaria slides). All rainy periods from April 1995 were followed by malaria seasons, although they were more difficult to define compared to those in Kagera. Malaria increased between May-August 1997 despite little preceding rain. ENSO (October 1997-May 1998 ) was followed by a malaria season of the same magnitude as in Kagera(Figure 1). During all these periods, including ENSO, there was a high incidence of malaria with $600-900$ positive malaria slides per month. Diagnosed malaria cases in the paediatric ward and positive malaria slides for the whole population showed good temporal correlation.

There were 7,350 singleton live and stillbirths at Kilosa hospital during 1994-1999, of which $1.4 \%$ had missing data (Table 1). The prevalence of low birthweight among primigravidae was $25.5 \%(95 \% \mathrm{CI}, 23.9-27.1)$, and among multigravidae $12.2 \%$ (95\% CI, 14.9-17.6). The proportion of primigravidae births was $39.7 \%$. As for Kagera, the peak risk period for increased low birthweight in primigravidae and multigravidae was estimated as commencing three months after the major malaria peak and lasting for five months [17]. The stillbirth rate was sig- 
nificantly lower in primigravidae (4.2\%; 95\% CI, 3.4-4.9) than in multigravidae (5.2\%; 95\% CI, 4.5-5.8, $\mathrm{p}=0.049$ ). Forty-four percent of stillbirths were low birthweight. Macerated stillbirth prevalence was $49 \%$, fresh stillbirth $32 \%$ and undefined stillbirths $19 \%$.

For the years 1997-1999, the prevalence of stillbirth and low birthweight was compared between malaria normal seasons, in connection with malaria seasons, and during and after ENSO. For Ndolage stillbirth and low birthweight prevalence were both significantly increased for all malaria seasons combined when compared to periods between malaria seasons ( $p=0.002$ and $p=0.004$ respectively). For Kilosa there was no significant difference in prevalence of these outcomes for the same comparison. Comparisons of outcomes for specific malaria seasons are listed in Tables 2 and 3.

Comparing Ndolage and Kilosa for the years 1997-1999, there was a significant difference in stillbirth prevalence between Ndolage and Kilosa between malaria seasons $(2.4 \%$ and $5.6 \%$ respectively, $\mathrm{p}<0.001)$ and during malaria seasons $(1.9 \%$ and $5.9 \%$ respectively, $\mathrm{p}<0.001)$. During ENSO there was no difference, as prevalence increased in Ndolage, (4.1\% and $4.9 \%$, respectively) (Table 3). There was a significant difference in low birthweight prevalence between Ndolage and Kilosa between malaria seasons $(14.4 \%$ and $23.0 \%$ respectively, p < $0.001)$ and in relation to more normal malaria seasons $(13.9 \%$ and $25.2 \%$ respectively, $\mathrm{p}<0.001)$. During ENSO there was no difference as prevalence had increased in Ndolage (22.2\% and $19.8 \%$, respectively).

\section{Discussion}

This study reports for the first time a retrospective analysis of seasonal patterns of both low birthweight and stillbirth prevalence in relation to malaria endemicity during high malaria transmission periods and parity. It also reports on the varying risk of low birthweight or stillbirth in different parts of one country with differing malaria transmission patterns and the data coincides for the two areas for the period 1994-1999 (6 years). The analysis is limited as it was retrospective and based on hospital data. Community data on stillbirths would be difficult to obtain without a population-based field study.

The Kagera region, where Ndolage hospital is situated, was hit by an unusual seasonal malaria transmission that led to a severe epidemic during the study period 19941999. Standing water after the rainy season became a problem during ENSO 1997-1998 with the consequence of an unusual long and intense malaria transmission season (10 months). During 1994 there was unusually heavy rain and increased Plasmodium falciparum positivity with, as a consequence, a prolonged malaria season, but this was not as severe as 1997-1998. Other periods showed seasonal rainfall patterns with malaria seasons mostly lasting 2-4 months.

During the heavy malaria season 1994 and the ENSO low birthweight prevalence in primigravidae was $22.0 \%$, compared to between 14-15\% during the periods between and in relation to malaria seasons. The selective effect of increased low birthweight prevalence on primigravidae suggested that malaria was the primary cause of this differential effect between primigravidae and multigravidae [8]. For the years 1997-1999 and comparing Ndolage and Kilosa there was a significant difference for the risk of low birthweight in primigravidae between and during normal malaria seasons, but a similar prevalence during ENSO. In Morogoro region, where Kilosa hospital is situated, malaria was holoendemic with perennial malaria. As the

Table 3: Comparison of Ndolage and Kilosa delivery data between, 1997-1999

\begin{tabular}{|c|c|c|c|c|c|c|c|}
\hline \multirow[t]{2}{*}{ Malaria transmission level } & \multirow[t]{2}{*}{ Location } & \multicolumn{3}{|l|}{ Stillbirth* } & \multicolumn{3}{|c|}{ Low birthweight** } \\
\hline & & All & PG & MG & All & PG & MG \\
\hline \multirow[t]{4}{*}{ Between malaria seasons } & Ndolage & 2.4 & 1.2 & 3.2 & 9.8 & 14.4 & 7.1 \\
\hline & Kilosa & 5.6 & 4.6 & 6.3 & 15.4 & 23.0 & 10.0 \\
\hline & Odds ratio & $2.4(1.7-3.5)$ & $2.9(1.8-8.5)$ & $2.1(1.3-3.1)$ & $1.68(1.36-2.07)$ & $1.8(1.3-2.4)$ & $1.5(1.1-2.0)$ \\
\hline & $\mathrm{p}$-value & $<0.001$ & $<0.001$ & $<0.001$ & $<0.001$ & $<0.001$ & 0.021 \\
\hline \multirow[t]{4}{*}{ Malaria seasons } & Ndolage & 1.9 & 2.5 & 1.4 & 11.7 & 13.9 & 9.8 \\
\hline & Kilosa & 5.9 & 5.1 & 6.5 & 16.5 & 25.2 & 10.2 \\
\hline & Odds ratio & $3.2(1.7-5.9)$ & $2.1(0.9-5.3)$ & $4.98(2.08-11.92)$ & $1.5(1.2-1.9)$ & $2.1(1.4-3.0)$ & I.I $(0.8-1.6)$ \\
\hline & $\mathrm{p}$-value & $<0.001$ & $>0.05$ & $<0.001$ & 0.001 & $<0.001$ & $>0.05$ \\
\hline \multirow[t]{4}{*}{ ENSO } & Ndolage & 4.1 & 3.5 & 4.5 & 12.4 & 22.2 & 7.4 \\
\hline & Kilosa & 4.9 & 3.3 & 5.9 & 14.6 & 19.8 & II.I \\
\hline & Odds ratio & $1.2(0.8-1.8)$ & $0.9(0.4-2.1)$ & I.3 (0.8-2.2) & I.2(0.8-I.8) & $0.9(0.5-1.5)$ & $1.6(0.9-2.8)$ \\
\hline & $\mathrm{P}$-value & $>0.05$ & $>0.05$ & $>0.05$ & $>0.05$ & $>0.05$ & $>0.05$ \\
\hline
\end{tabular}

*twins excluded** twins and stillbirth excluded, risk period for low birthweight is calculated to start 3 months after the peak malaria period and to last for 5 months. 


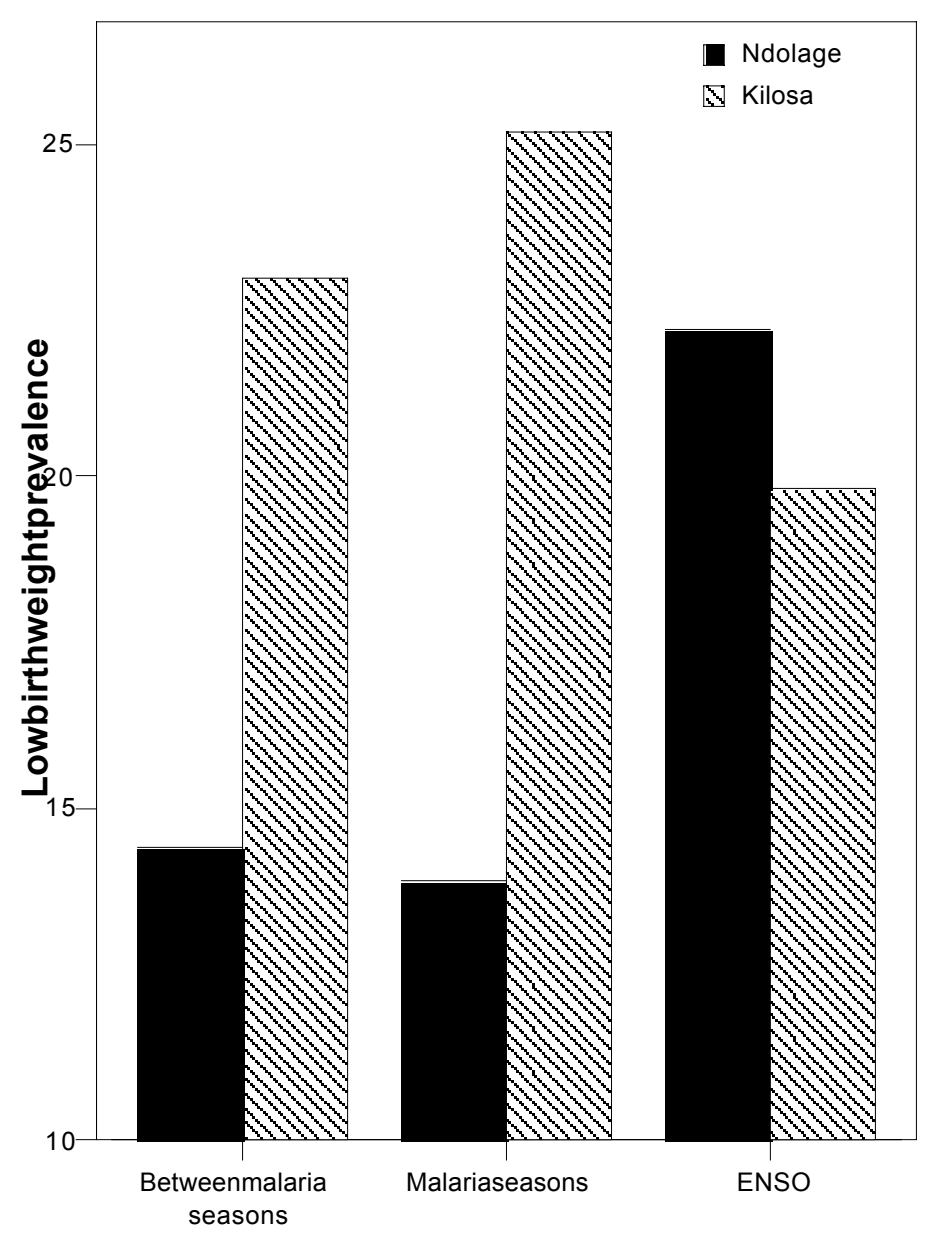

Figure 3

Low birthweight risk during periods with different malaria transmission intensity (1997-1999).

area is very flat, with a high risk of standing water even after moderate rains, this provided sufficient breeding sites for mosquitoes. Periods were identified when malaria diagnoses were increased and classified these as malaria seasons and considered there was persistent transmission between rainy seasons, due probably to the effects of standing water. Smith et al. carried out a malariometric survey in two villages, situated in the Morogoro region and showed a high prevalence of $P$. falciparum parasitaemia [22]. The estimated mean annual inoculation rate was over 300 infectious bites per person per year with no seasonal fever pattern among children and adults. This constant malaria pressure must have contributed to increasing the risk of low birthweight among primigavidae $(25.5 \%)$ as first pregnancies are at greatly increased risk of falciparum malaria $[2,3,6]$. This could relate to the higher risk of stillbirth $(4.8 \%)$ at Kilosa hospital, which was double that for Ndolage.
Potentially confounding factors which could influence prevalence of stillbirth and low birthweight should be considered [23]. HIV infection has a low prevalence in Kagera region $(4.7 \%)$, but higher in Morogoro region (9.0\%) [24]. HIV incidence is unlikely to alter seasonally, although it is possible that HIV viral load could vary seasonally with associated malaria parasitaemia [25]. The increased incidence of malaria with HIV infection as a combined infection could increase perinatal mortality and stillbirth risk. Syphilis which is an important cause of stillbirth is unlikely to be seasonal although the prevalence in either population is not low (14.9\% in Kagera and $12.0 \%$ in Morogoro [24]. Nutritional factors could be important and in Kagera crop production during 1997/ 1998 was good, especially for bananas and sweep potatoes. October was the only month with significantly higher risk for stillbirth, but there is little risk of food shortage then because of harvesting during June-October. 


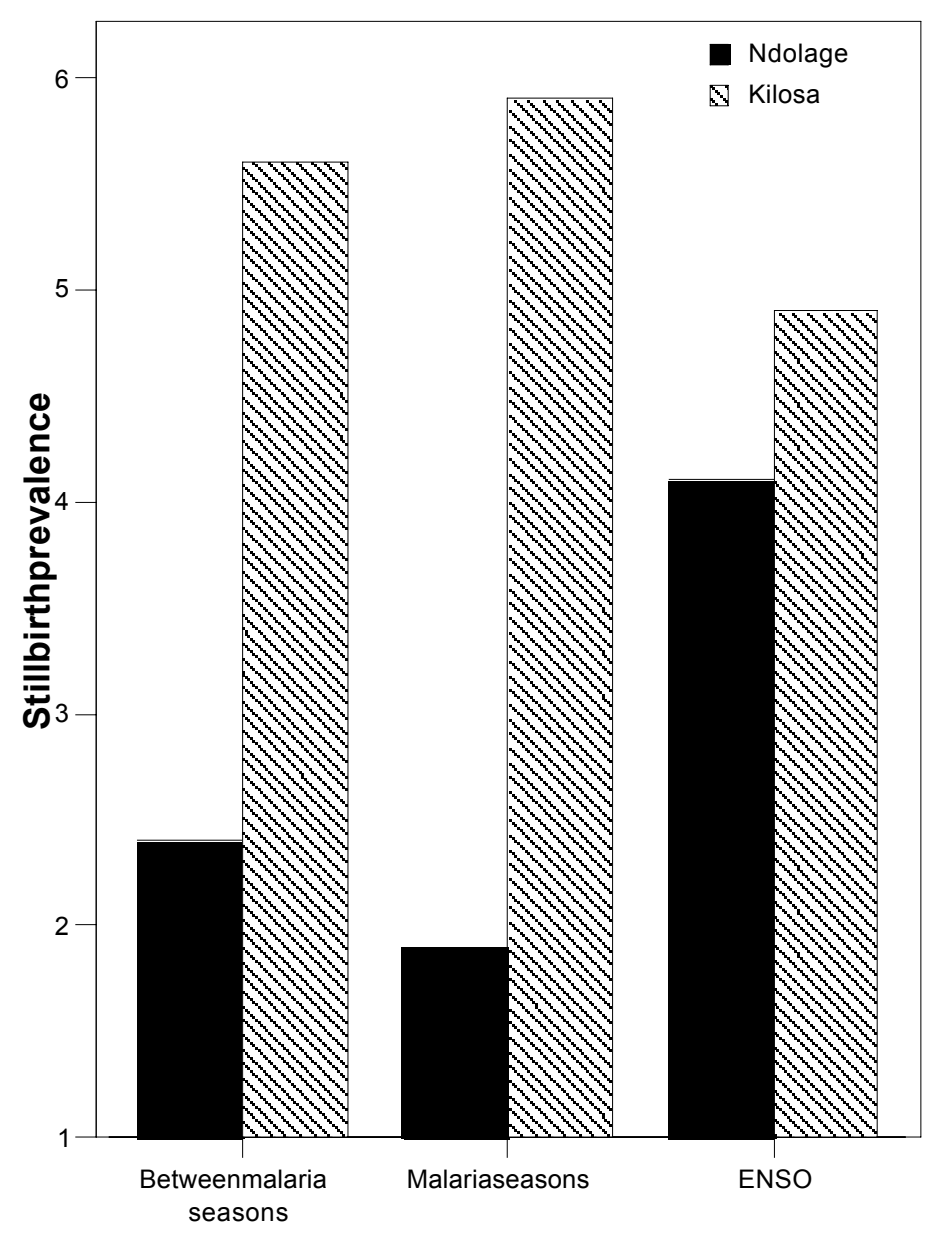

Figure 4

Stillbirth risk during periods with different malaria transmission intensity (1997-1999).

In Morogoro the food production dropped by $31 \%$ during the ENSO period due to standing water, but the population had good access to staple food [26]. Eclampsia, which is more common in first pregnancies and preeclampsia have been associated with malaria exposure in some studies $[2,27,28]$. Nevertheless the incidence of these conditions is too low to account for the large variation in low birthweight and stillbirth prevalence observed between locations in this analysis.

This data indicates that pregnant women in Kilosa live under a constant high pressure of malaria. During ENSO 1997-98, there was a prolonged malaria season. Despite the immense impact of malaria, there was no significant increased risk of low birthweight or stillbirth during this period. Malaria pressure may have reached a limit in terms of its effect on excess risk of low birthweight in primigravidae, or of stillbirth risk across all parities.
In areas with holoendemic malaria, such as Morogoro, semi-immune women often experience sub-clinical parasitaemias and risk of stillbirth in asymptomatic women may be smaller [8]. In areas with lower endemicity, such as in Kagera, and where host immunity is less developed, the risk of stillbirth would be increased, which was observed at Ndolage hospital. Under these conditions greater fluctuations in stillbirth prevalence would result with seasonal or epidemic malaria, as occurred in Kagera. Women of all parities were at increased risk, although this was highest for multigravidae. Several studies have reported a greater effect of malaria on perinatal mortality in primigravidae than multigravidae $[3,5,29,30]$. As low birthweight is the single most important risk factor for neonatal mortality [31-34] and the risk of low birthweight is considerably higher in primigravidae, then it might be expected they would experience higher perinatal mortality. This was not observed in the present study in terms of 
stillbirth risk. The high prevalence is likely to have other causes in addition to malaria. Stillbirths whose birthweight was below $2.5 \mathrm{~kg}$ would comprise a group with possibly higher risk of congenital infections such as syphilis, and it was possible many babies died secondary to poor obstetric care.

The high prevalence of anaemia among pregnant women living in malarious areas indicates that foetal anaemia is common, especially in babies whose mothers have concurrent iron deficiency anaemia and high density placental malaria [11]. In these areas average cord haemoglobin may be as low as $13.5 \mathrm{~g} / \mathrm{dl}$. Birth in the rainy season has been associated with a 54\% incidence of foetal anaemia compared with $34.2 \%$ during the dry season [11] and foetal anaemia was associated with increased post-neonatal mortality in low birthweight babies [35]. Placental malaria could increase the risk for stillbirth through maternal and foetal anaemia, and these babies must be more vulnerable to any kind of birth complication (e.g. cord around the neck, or prolonged labour). This could explain the high prevalence stillbirth in Kilosa and an increased malaria related risk of stillbirth during ENSO in Ndolage.

This analysis, shows that malaria exposure during pregnancy had a delayed effect on birthweight outcomes, but a more acute effect on stillbirth risk. The birthweight effect occurred 3-8 months after the peak time of malaria exposure. This is consistent with chronic pregnancy parasitaemias in mid-pregnancy leading to foetal growth restriction, which would be detectable at delivery, a number of months after the peak period of malaria exposure. A recent review of placental malaria has shown that foetal growth restriction is commoner than pre-term delivery with chronic placental infection [36]. This would explain why birthweight was not reduced in primigravidae in relation to the short but intensive malaria period July-August 1997. The effect on stillbirth was greatest during the established malaria epidemic in Ndolage in 19971998, suggesting a more acute pathway was involved for stillbirth risk at the time of delivery. This is consistent with the detailed observations of McGregor in the Gambia [3], who reported lower stillbirth rates (all parities) during the three months of the late dry season. In the present study the risk was also lowest during the period between or in connection with ordinary malaria seasons.

This study has also shown that the risk of delivering a low birthweight baby in the first pregnancy increases approximately five months following a malaria epidemic and that the risk of stillbirth almost doubles. The analysis shows a greatly increased low birthweight risk in primigravidae in relation to the heavy malaria season 1994 and ENSO, and also a greatly increased risk of stillbirth in all parities, related to the ENSO of 1997-1998. The areas from which data was collected are considered to experience endemic malaria transmission, but the patterns of exposure during pregnancy and its effects on pregnancy outcome vary to a much greater extent than anticipated across different years.

The use of rainfall for monitoring for malaria early warning has been proposed as a methodology for prediction, prevention and control of malaria epidemics $[37,38]$. This analysis provides evidence that poor pregnancy outcomes are linked to ENSO years. As a consequence, improved predictions related to climatic factors offers the opportunity for intensifying malaria control measures in order to improve malaria control in pregnancy. This is of particular relevance for communities whose use of malaria control measures in pregnancy is poor. It is essential to provide adequate antimalarial protection to pregnant women, using intermittent preventive treatment and impregnated bed nets, in order to improve pregnancy outcomes. This approach requires adequate monitoring of birthweight indices and stillbirth prevalence $[31,40]$. Much of this data is routinely collected in hospital facilities but not utilised for surveillance purposes. Improved delivery data acquisition and analysis will be required to successfully harness this approach to strategies to improve malaria control in pregnancy, especially in sub-Saharan Africa.

\section{Authors' contributions}

UW completed the field study and preliminary analysis. IH advised on the study design and statistical analysis. TM assisted with interpretation of data and with writing the paper. BB proposed the study and assisted in its design, analysis, interpretation and in writing the paper.

\section{Acknowledgements}

Maud and Birger Gustavsson's Stiftelse that supported part of the project economically. Marian Warsame who helped UUW in Kilosa, the staff of Kilosa Hospital and Dr Arne Kjellgren assisted in Ndolage. Father Fidon Mwombeki from ELCT who gave permission for the study to be undertaken in Ndolage Hospital. The work was partly supported by a grant from the European Commission Research Directorate General Fifth Framework (contract PREMA-EU-ICA4-ct-200I-I I I00I2).

\section{References}

I. van Geertruyden JP, Thomas F, Erhart A, d'Alessandro U: The contribution of malaria in pregnancy to perinatal mortality. Am J Trop Med Hyg 2004, 7 I:35-40.

2. Brabin BJ, Johnson PM: Placental malaria and pre-eclampsia through the looking glass backwards? J Reproductive Immunol 2005, 65: $1-15$.

3. McGregor IA, Wilson ME, Billewicz WZ: Malaria infection of the placenta in The Gambia, West Africa; its incidence and relationship to stillbirth, birthweight and placental weight. Trans Roy Soc Trop Med Hyg 1983, 77:232-244.

4. Nosten F, ter Kuile F, Maelankirri L, Decludt B, White NJ: Malaria during pregnancy in an area of unstable endemicity. Trans $R$ Soc Trop Med Hyg 1991, 85:424-429.

5. Steketee RW, Wirima JJ, Hightower AW, Slutsker L, Heymann DL, Breman JG: The effect of malaria and malaria prevention in 
pregnancy on offspring birthweight, prematurity, and intrauterine growth retardation in rural Malawi. Am J Trop Med Hyg 1996, 55:33-4I.

6. Verhoeff FH, Brabin BJ, Chimsuku L, Kazembe P, Russell WB, Broadhead RL: An evaluation of the effects of intermittent sulfadoxine-pyrimethamine treatment in pregnancy on parasite clearance and risk of low birthweight in rural Malawi. Ann Trop Med Parasitol 1998, 92:14I-I 50.

7. Uddenfeldt Wort U, Hastings I, Carlstedt A, Mutabingwa TK, Brabin BJ: Impact of EI Niño and malaria on birthweight in two areas of Tanzania with different malaria transmission patterns. Int J Epidemiol 2004, 33:|31 I-1319.

8. Brabin BJ: The Risks and Severity of Malaria in Pregnant women. In Applied Field Research in Malaria Reports Volume I. Geneva: World Health Organization; 1991.

9. Anagnos D, Lanoie LO, Palmieri JR, Ziefer A, Connor DH: Effects of placental malaria on mothers and neonates from Zaire. $Z$ Parasitenkd 1986, 72(I):57-64.

10. Okoko BJ, Ota MO, Yamuah LK, Idiong D, Mkpanam SN, Avieka A, Banya WA, Osinusi K: Influence of Placental Malaria Infection on Foetal Outcome in the Gambia: Twenty years after lan McGregor. J Hlth Population Research 2002, 20(I):4-II.

1I. Brabin B], Kalanda BF, Verhoeff FH, Chimsuku LH, Broadhead RL: Risk factors for foetal anaemia in a malarious area of Malawi. Ann Trop Paeds 2004, 24:3 I I-32I.

12. Cot M, Deloron P: Malaria prevention strategies. $\mathrm{Br}$ Med Bull 2003, 67:| $37-48$.

13. Ndyomugyenyi R, Magnussen P: Malaria morbidity, mortality and pregnancy outcome in areas with different levels of malaria transmission in Uganda: a hospital record-based study. Trans $R$ Soc Trop Med Hyg 200I, 95(5):463-68.

14. Jamieson DJ, Meikle SF, Hillis SD, Mtsuko D, Mawji S, Duerr A: An Evaluation of Poor Pregnancy Outcomes among Burundian Refugees in Tanzania. JAMA 2000, 283(3):397-402.

15. Newman RD, Hailemariam A, Jimma D, Degifie A, Kebede D, Rietveld $A E$, Nahlen BL, Barnwell JW, Steketee RW, Parise ME: Burden of malaria during pregnancy in areas of stable and unstable transmission in Ethiopia during a non-epidemic year. J Infect Dis 2003, I 87( I I): 1765-72

16. Andersson T, Högberg U, Bergström S: Community-based prevention of perinatal deaths: lesson from nineteen-century Sweden. Int J Epidemiol 2000, 29:542-548.

17. Uddenfeldt Wort U: Effect of a Malaria Epidemic on Birthweight in an Area with Seasonal Malaria. In Master of Science in International Health, Degree Project Report Series, 2000:I Department of Women's and Children's Health, Uppsala University.

18. Tanzanian Ministry of Health: Health Statistics Abstract: Morbidity and Mortality Data. 1999, I:

19. Makundi EA, Malebo HM, Mhane P, Mitua AY, Warsame M: Rule of traditional healers in the management of severe malaria among children below five years of age: the case of Kilosa and Handeni Districts, Tanzania. Malar J 2006, 5:58.

20. Eriksen J, Mwankusye S, Mduma S, Kitua A, Swedberg G, Tomson G, Gustafsson LL, Warsame M: Patterns of resistance and DHFR/ DHPS genotypes of Plasmodium falciparum in rural Tanzania prior to the adoption of sulfadoxine-pyrimethamine as firstline treatment. Trans $R$ soc Trop Med Hyg 2004, 98:347-353.

21. Thompson B, Baird D: Some impressions of childbearing in tropical areas. J Obst Gynaecol Br Comm I967, 74:329-338.

22. Smith T, Charlwood JD, Kihonda J, Mwankusye S, Billingsley P, Meuwissen J, Lyimo E, Takken W, Teuscher T, Tanner M: Absence of seasonal variation in malaria parasitaemia in an area of intense seasonal transmission. Acta Tropica 1993, 54:55-72.

23. MClure EM, Nalubamba-Phiri M, Goldenberg RL: Stillbirth in developing countries. Int J Gynecol Obstet 2006, 94:92-90.

24. Swai RO, Somi GR, Matee MIN, Lyamuya EF, Killewo J, Kwesigabo G, Tulli T, Kabalimu TK, Ng'ang'a L, Isingo R, Ndayongeje J: Surveillance of HIV and syphilis infections among antenatal clinic attendees in Tanzania-2003/2004. [http://www.biomedicalcen tral.com/|47|-2458/6/9|].

25. ter Kuile FO, Parise ME, Verhoeff FH, Udhayakumar V, Newman RD, van Eick AM, Rogerson SJ, Steketee RW: The burden of co-infection with human immuno-deficiency virus type $I$ and malaria in pregnant women in sub-Saharan Africa. Am J Trop Med Hyg 2004, 71:41-44.
26. FAO/WFP: Crop and Food Supply Assessment Mission to Tanzania. Special Report. 1998.

27. Sartelet H, Rogier C, Milko-Sartelet I, Angel G, Michel G: Malaria associated with pre-eclampsia in Senegal. Lancet 1996, 347:1121.

28. Bergström S, Povey G, Songane F, Ching C: Seasonal incidence of eclampsia and its relationship to meteorological data in Mozambique. J Perinatal Med 1992, 20:153-158.

29. Reinhardt MC, Gautier R, Reinhardt NM: A study of 204 consecutive deliveries in Abidjan - Anthropometric data of newborns, mothers and placentas. Helv Paediat Acta 1978, 41:2 I-42.

30. Greenwood AM, Armstrong IR, Byass P. Snow RW, Greenwood BM: Malaria chemoprophylaxis, birth weight and child survival. Trans Roy Soc Trop Med \& Hyg 1992, 86:483-485.

31. Victora CG, Smith PG, Vaughan IP, Nobre LC, Lombardi C, Teixeira AM, Fuchs SC, Moreira LB, Gigante LP, Barros FC: Influence of birth weight on mortality from infectious diseases: a casecontrol study. Pediatrics 1988, 81:807-I I.

32. Brabin BJ: An analysis of malaria in pregnancy in Africa. Bull Wrld HIth Org 1983, 61:1005-16.

33. Lira PI, Ashworth A, Morris SS: Low birth weight and morbidity from diarrhea and respiratory infection in northeast Brazil. J Pediatrics 1996, I 28:497-504.

34. Guyatt HL, Snow BW: Malaria in pregnancy as an indirect cause of infant mortality in sub-Saharan Africa. Trans Roy Soc Trop Med Hyg 200I, 95:569-576.

35. Verhoeff FH, Le Cessie S, Kalanda BF, Kazembe PN, Broadhead RL, Brabin B]: Post-neonatal infant mortality in Malawi: the importance of maternal health. Ann Trop Paediatr 2004, 24:161-169.

36. Brabin BJ, Romagosa $\mathrm{C}$, Abdelgalil $\mathrm{S}$, Menéndez $\mathrm{C}$, Verhoeff $\mathrm{FH}$, McGready R, Fletcher KA, Owens S, d'Alessandro U, Nosten F, Fisher PR, Ordi J: The sick placenta -The role of Malaria. Placenta 2004, 25:359-378.

37. Thomson MC, Mason SJ, Phindela T, Connor SJ: Use of rainfall and sea surface temperature monitoring for malaria early warning in Botswana. Am J Trop Med Hyg 2005, 73:2/4-22I.

38. Bouma MJ: Epidemiology and Control of Malaria in Northern Pakistan. In PhD thesis University of Leiden; 1995.

39. Brabin B]: An assessment of low birthweight in primiparae as an indicator of malaria control in pregnancy. Int J Epid I99I, 20:276-283.

40. Bouma MJ, Brabin BJ: Can we use birthweight to monitor changes in malaria epidemiology in the Ethiopian highlands. In Abstract (M I O). British Society for Parasitology Annual Meeting Chester UK; 2004.
Publish with Biomed Central and every scientist can read your work free of charge

"BioMed Central will be the most significant development for disseminating the results of biomedical research in our lifetime. "

Sir Paul Nurse, Cancer Research UK

Your research papers will be:

- available free of charge to the entire biomedical community

- peer reviewed and published immediately upon acceptance

- cited in PubMed and archived on PubMed Central

- yours - you keep the copyright
BioMedcentral 